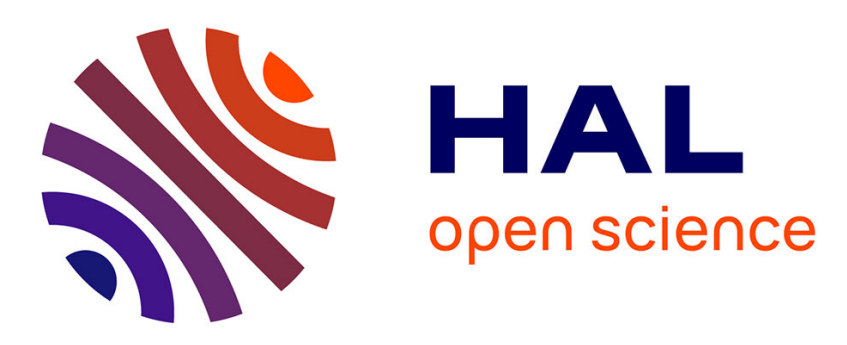

\title{
Studying Vowel Variation in French-Algerian Arabic Code-switched Speech
}

Jane Wottawa, Djegdjiga Amazouz, Martine Adda-Decker, Lori Lamel

\section{To cite this version:}

Jane Wottawa, Djegdjiga Amazouz, Martine Adda-Decker, Lori Lamel. Studying Vowel Variation in French-Algerian Arabic Code-switched Speech. Interspeech 2018, Sep 2018, Hyderabad, India. pp.2753-2757, 10.21437/Interspeech.2018-2381 . halshs-02130906

\section{HAL Id: halshs-02130906 \\ https://shs.hal.science/halshs-02130906}

Submitted on 16 May 2019

HAL is a multi-disciplinary open access archive for the deposit and dissemination of scientific research documents, whether they are published or not. The documents may come from teaching and research institutions in France or abroad, or from public or private research centers.
L'archive ouverte pluridisciplinaire HAL, est destinée au dépôt et à la diffusion de documents scientifiques de niveau recherche, publiés ou non, émanant des établissements d'enseignement et de recherche français ou étrangers, des laboratoires publics ou privés. 


\title{
Studying vowel variation in French-Algerian Arabic code-switched speech
}

\author{
Jane Wottawa ${ }^{1}$,Djegdjiga Amazouz ${ }^{1,2}$, Martine Adda-Decker $^{2}$, Lori Lamel $^{1}$ \\ ${ }^{1}$ LIMSI, CNRS, Université Paris-Saclay, France \\ ${ }^{2}$ LPP, UMR 7018 CNRS - U. Paris 3 / Sorbonne Nouvelle, France \\ [wottawa, amazouz, madda, lamel] alimsi.fr
}

\begin{abstract}
Algerian Arabic-French bilinguals show phonetic variation with respect to vowel timber in both their languages. Our study aims to automatically identify vowel variants frequently produced by such bilinguals. To that end, the speech corpus FACST, containing French and Algerian Arabic code-switched speech, was analyzed. A second corpus with native French speakers (NCCFr) was used to provide a reference baseline and to compare vowel variants across the two speaker groups. Three experiments were carried out: first, the French speech of both corpora was aligned with a French acoustic model including parallel nearest-neighbor vowel variants in its pronunciation dictionary. Second, the Arabic speech was aligned using the same acoustic model with parallel vowel variants in its dictionary. Finally, we tested whether peripheral vowels in Algerian Arabic-French bilinguals are more often centralized than in French native speech by allowing schwa as a competing variant. The results show that French natives and Algerian ArabicFrench bilinguals globally have a comparable amount of vowel variation in French. However, French natives have stable high vowels whereas bilinguals tend to produce stable low and back vowels. In the centralization experiment, Algerian bilinguals favor the centralization of mid, open and back vowels.

Index Terms: Vowel variation, Code-switched speech, French, Algerian Arabic.
\end{abstract}

\section{Introduction}

It has been shown that bilingual speakers' speech presents more acoustic variation than speech of monolinguals [1,2]. This is explained by the fact that bilinguals have access to more than one phonemic inventory which may lead to potential interferences $[3,4]$. The proposed study focuses on French-Algerian code-switched speech, with bilingual speakers having access to both French and Arabic phonemic inventories. French features a much higher number of vowels than does Algerian Arabic. This makes it particularly interesting to study code-switched (CS) speech [5] and investigate how the increase in complexity of the vowel inventory induced by CS is handled by our bilingual Algerian speakers of French and Arabic. To this end, we propose to compare French vowel production variation in Algerian Arabic-French bilinguals and in French (FR) native speakers. Furthermore, we will compare their French productions (FR-Alg) to their speech productions of Algerian Arabic (AA) in CS context $[6,7]$. The aim of the study is to shed some light on the pronunciation variation Algerian Arabic-French bilinguals produce in both languages and in CS speech. To measure vowel production variation we make use of an automatic speech alignment system which includes vowel-specific pronunciation variants in its pronunciation lexicon. The general idea is the following: if during the alignment a vowel is frequently replaced by one of the proposed competing vowels, this is considered as an indicator of variation.
In our study, we focus on parallel variants $[8,9]$, but do not address phoneme insertion or deletion. Parallel variants present changes in the sound chain which allow multiple choices at a given position. For example, the word série [seri] (series) could have [siri] as a parallel variant if [i] is one of the possible variants of [e].

The remainder of this paper is as follows. First a brief comparison between the FR and AA vowel systems is provided, followed by a presentation of the speech corpora used in this investigation. Next, the methodology is presented followed by the results and their discussion. The study ends with general conclusions and perspectives for future research.

\section{French and Algerian Arabic vowels}

Nowadays, the French vowel system tends to be described using eleven oral vowels and three nasal vowels [10]. Referring to the spelling and transliteration of AA [11, 12], the language counts six oral vowels contrasting in duration (3 short vowels, 3 long vowels). The AA vowels are [i, a, u, is, a:, u:]. The comparison of the two vowel systems shows that French has a richer vocalic system than AA. The eleven oral vowels of French are [i, e, $\varepsilon$, $\mathrm{y}, \varnothing, \propto$, , $\mathrm{a}, \supset, \mathrm{o}, \mathrm{u}]$. French also has the following three nasal vowels $[\tilde{\varepsilon}, \tilde{a}, \tilde{\jmath}]$, and in some regional varieties, a fourth nasal

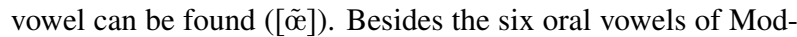
ern Standard Arabic, AA is often described with an additional long vowel [e:] [13]. However, this vowel has not yet been introduced in our pronunciation lexicon because of its missing grapheme correspondence in the Arabic orthography.

\section{Speech material}

In this study the French Algerian Code-switching Triggered (FACST) corpus of French and Algerian Arabic speech from Algerian Arabic-French bilinguals was used. Details of this corpus which contains both read and spontaneous speech can be found in $[12,14]$. The corpus contains a total of 7:30h of read and stimulated spontaneous speech with code-switching [15, 16] in both French and Algerian Arabic of 20 speakers (10 female). To date the data from 11 speakers, ca. 3 hours has been fully transcribed and verified and is used in the present study.

Furthermore, the Nijmegen Corpus of Casual French (NCCFr) is also used in the analyses in order to provide a reference baseline for vowel variation in French spontaneous speech. The corpus contains about $36 \mathrm{~h}$ of conversational French of 46 speakers ( $24 \mathrm{female}$ ) raised in Central/Northern France. More detailed information about this corpus can be found in [17].

\section{Methodology}

This section describes the methodology used to study vowel variants via automatic speech-text alignments with lexicons including pronunciation variants for 3 series of experiments with targeted contrasts. 


\subsection{Automatic alignment}

The automatic alignment of the parallel vowel variants across both speech corpora and for each one of the three experiments was realized using a set of position-independent monophone acoustic models similar to those described in $[18,19,20,21]$. This setup was used as previous studies showed that since the large sets of context-dependent acoustic models typically used in speech recognition systems, capture some of the coarticulatory variation, there is less of a need for the system to select a different phoneme than the canonical one $[8,9]$. The alignment system locates word and phone boundaries using the orthographic transcriptions and the best matching pronunciations chosen among the pronunciation variants that are included in its dictionary. Typical pronunciation variants in French are due to optional liaison consonants and schwa vowels (which may be described as sequential variants), allowing for one more or one less phone symbol in the pronunciation. Other typical variants are due to word-final consonant cluster simplifications as in the word autre (other) which provides the following choices to the system: [otr], [otr], [otrə], [otrə], [ot], [ot]. This particular example combines both parallel ([o,o]) and sequential (optional $[\mathrm{r}]$ and $[ə]$ ) variants. However, in general, most lexical entries tend to be described by their canonical (full form) pronunciation.

This method is more objective than human transcriptions however the vowel choices are categorical. In order to capture gradual variations, complementary analyses carried out by humans are necessary.

\subsection{Production variation quantification}

Production variation is quantified for each target vowel by measuring the rates of the corresponding competing vowels that are selected during the automatic alignment phase. For instance, if all occurrences of a given target vowel were aligned unchanged without making use of any of the competing variants, the variation rate would be $0 \%$. In the result section, for each experiment, the variation will be described with the help of variant rates indicating the proportion of occurrences of a target vowel that were replaced by a competing vowel.

\subsection{Vowel variants in French: French natives vs. bilinguals}

In the first experiment, we start measuring vowel production variation using the proposed method with spontaneous speech of French native speakers to establish a reference. Then, we apply exactly the same method to the French and Algerian speech parts of our bilingual speakers [22, 23], however our analyses focus on the French productions. Production variation is measured for five target vowels, where each target vowel is put in parallel with two competing variants. A specific pronunciation variant lexicon is built for each condition. The defined target vowels are the peripheral vowels $[\mathrm{i}, \mathrm{e}, \mathrm{a}, \mathrm{o}, \mathrm{u}]$ with competing variants as shown in Table 1. For each target vowel, competing variants were chosen as the two nearest neighbors towards the center of the vocalic space (triangle) with respect to the target vowel's location. For the open vowel [a], we tested two different configurations, termed as anterior and posterior. We also included $/ \mathrm{i} /$ as a variant for $/ \mathrm{e} /$, and $/ \mathrm{y} /$ as a variant for $/ \mathrm{u} /$. Our initial analyses indicate that there is no significant change to the results without these extra variants.

The different pronunciation variant lexicons were tested on both corpora (French native NCCFr and the French speech subset of the bilingual FACST corpus) using the LIMSI automatic alignment system with French native acoustic models.
Table 1: Competing vowel variants for each target vowel.The last column exemplifies the effect on the pronunciation lexicon. Note that for the most open [a] vowel, two sets of variants (ante, post) are proposed.

\begin{tabular}{|c|c|c|}
\hline $\begin{array}{l}\text { Target } \\
\text { vowel }\end{array}$ & $\begin{array}{l}\text { Competing } \\
\text { variants }\end{array}$ & Example \\
\hline [i] & {$[\mathrm{e}, \mathrm{y}]$} & lit (bed) : li, le, ly \\
\hline [e] & {$[\varepsilon, \infty]$} & nez (nose) : ne, ne nœ \\
\hline [a] & $\begin{array}{l}{[\varepsilon, \propto]} \\
{[\supset, œ]}\end{array}$ & $\begin{aligned} \text { chat (cat) } & : \int a, \int \varepsilon, \int œ \text { (anterior) } \\
\text { (cat) } & : \int a, \int \partial, \int œ \text { (posterior) }\end{aligned}$ \\
\hline [o] & {$[0, \varnothing]$} & chaud (hot) : $\int \mathrm{o}, \int \mathrm{\rho}, \int \varnothing$ \\
\hline$[\mathrm{u}]$ & {$[0, \varnothing]$} & loup (wolve) : lu, lo, lø \\
\hline
\end{tabular}

\subsection{Vowel variants in code-switching}

In the following, only speech from the FACST corpus was used. Here, we focus on vowel production variation in bilingual speakers as a function of the spoken language, French (FR) or Algerian Arabic (AA). We limit the investigations to the three cardinal vowels $[\mathrm{i}, \mathrm{a}, \mathrm{u}]$ which are shared by the two phonological vowel systems. For each of the three target vowels, the same competing vowels are used as in the first experiment.

The automatic alignment system was still based on French acoustic models. As the French inventory contains more vowels, the French acoustic models allow us to quantify what happens in a larger number of smaller vocalic locations in the Algerian Arabic vowel space. It is noteworthy to remind that the use of French acoustic models should not lead to interpretations such as aligned variants correspond to realizations of French phonemes, but rather that the realization of an Arabic vowel is acoustically close to that of French vowels.

\subsection{Vowel centralization in French and code-switching}

In this experiment, we aim at quantifying whether the acoustic realizations of the peripheral vowels tend to move towards the center by simply testing one single competing vowel, the [ə] schwa. We also added the three nasal vowels: $[\mathrm{i}, \mathrm{e}, \varepsilon, \mathrm{a}, \mathrm{\jmath}, \mathrm{o}, \mathrm{u}$, $\tilde{\varepsilon}, \tilde{a}, \tilde{o}]$ and the following AA vowels i, a, u, is ,a: ,u. Considering [ə] schwa as the competing variant informs us about vowel reduction, which is also linked to vowel centralization [24]. This experiment allows us to measure whether the schwa variant is particularly productive in a CS context [25] and whether vowels tend to become more centralized.

\section{Results}

This section reports results for the 3 series of experiments aiming at quantifying vowel production variation, either by contrasting vowel substitution or by centralization for native French and bilingual Algerian-French speakers. Variant rates by vowel, by group/language as well as by group/language for each vowel were analyzed using the Chi-square test of independence.

\subsection{Vowel variants in French: French natives vs. bilinguals}

Figure 1 shows the vowel variant results as a function of the five vowel targets $[i, e, a, o, u]$. Variant rates are stacked starting from the bottom with the target vowel to which are added the two competing vowels. For each target vowel, the first stack of results corresponds to the French natives (as a reference) before the results of the French CS speech of the bilinguals are displayed. For the [a] target vowel, only the anterior variants are 


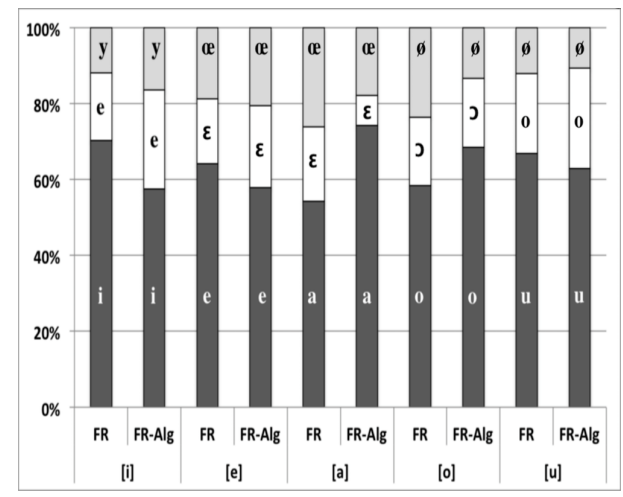

Figure 1: Expt 1: Vowel variants in native and code-switched French. For each target vowel on the $x$-axis, variant rates of native French $(F R)$ speakers are compared to those of Algerian French (FR-Alg). Variant rates are stacked and sum up to $100 \%$. [a] target results are shown for the anterior condition.

displayed as they turned out to be the most productive in native French and to produce globally similar results as the posterior variants in bilingual French.

Statistical analyses show no significant difference of variation across vowels $\left(\chi^{2}(10)=14.07, p=0.17\right)$. All vowel targets are equally likely to allow variants. Furthermore, both groups produce a comparable amount of vowel variants $\left(\chi^{2}(2)=0.64, p=0.73\right)$. In French, French-Algerian bilinguals are as likely as French native speakers to produce vowel variants. With respect to differences in vowel variant rates by group for each vowel, we observe significant differences only for the [a] target allowing anterior variants $\left(\chi^{2}(2)=9.76, p<\right.$ $0.01)$. In this vowel condition, French-Algerian bilinguals produce the [a] target significantly more often $(74.3 \%)$ than do French native speakers $(54.2 \%)$.

Finally, it is interesting to note that for the 3 vowels [i,a,u], the bilingual speakers have much larger variant rates in their native Algerian speech than in French. The following subsection sheds more light on variations between FR-Alg and AA speech.

\subsection{Vowel variants in code-switching}

In read speech, the tested variants show that vowels are less stable in AA than in FR-Alg speech produced by Algerian ArabicFrench bilinguals. Statistical analyses show that in read speech the variation rates differ according to the vowel $\left(\chi^{2}(6)=\right.$ 23.37, $p<0.001)$. For the target vowel [i] the first variant ([e] in our case) was chosen more often (31.6\%) than the other target vowels. Inversely, the first variant ([o]) of the target vowel [a] (post) was chosen significantly less often $(9.5 \%)$ compared to the first variant of the other target vowels. Furthermore, variation rates depend on the language the French-Algerian Arabic bilinguals are speaking $\left(\chi^{2}(2)=19.19, p<0.001\right)$. While reading in French, the bilingual speakers produce the target vowel significantly more often $(77.1 \%)$ than while reading in Algerian Arabic (47.5\%), leading to higher variation rates for the AA speech. With respect to variation rates by language for each vowel, we only observe no significant differences for the target vowel $[\mathrm{u}]\left(\chi^{2}(2)=1.25, p=0.54\right)$. For the target vowel [i], results show that the bilinguals differ regarding the variant $[\mathrm{e}]\left(\chi^{2}(2)=15.22, p<0.001\right)$. In French, the variant [e] was chosen only in $18.8 \%$ of the cases whereas in Algerian Arabic $44.1 \%$ of the [i] targets were aligned as [e]. With respect to the [a] target with both

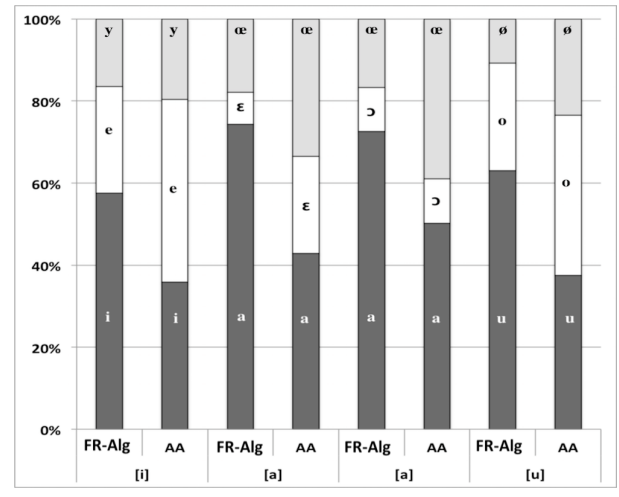

Figure 2: Expt 2: Vowel variants for bilingual Algerian-French speakers on the French $(F R)$ and Arabic $(A A)$ speech subsets of FACST CS data.

types of variants (ante: $\left(\chi^{2}(2)=50.76, p<0.001\right)$, post: $\left.\left(\chi^{2}(2)=36.31, p<0.001\right)\right)$, the bilinguals produce a high number of targets in French ([a] (ante): $86.0 \%$, [a] (post): $87.3 \%$ ) compared to their productions in Algerian Arabic ([a] (ante): $37.0 \%$, [a] (post): $48.6 \%$ ). As a consequence, in Algerian Arabic, variant rates for the anterior variants $[\varepsilon](25.0 \%)$ and $[œ](38.0 \%)$ are significantly higher than in French $([\varepsilon]$ : $6.2 \%$, [œ]: $7.8 \%$ ). With respect to the posterior variants for the target [a], only the variant [œ] appears more often in Algerian Arabic (38.7.0 \%) than in French $(6.4 \%)$.

CS speech is rather different from read speech especially for the AA part of the data. In FR-Alg, we observe that the target vowels were aligned as $[i, a, u]$ in most of the cases in both read and code-switched speech. Only the low score of $[\mathrm{u}]$ in read speech is an exception to that tendency. Statistical analyses show that vowel variation rate in CS speech is vowel dependant $\left(\chi^{2}(6)=25.52, p<0.001\right)$. Compared to the other target vowels, [i] allows the first variant ([e] in our case) more often $(35.3 \%)$. Inversely, for the target [a] with posterior variants, the first vowel variant [0] is produced less frequently $(10.7 \%)$ compared to the first variant of the other vowels. Moreover, language also has an impact on the vowel variant rates $\left(\chi^{2}(2)=\right.$ $12.96, p<0.01)$. Overall, French-Algerian bilinguals produce the target vowel more often in French $(63.0 \%)$ than they do in Algerian Arabic $(41.6 \%)$. Detailed analyses for each target vowel and its variants revealed that French-Algerian bilinguals significantly modify their speech production according to the language ([i]: $\left(\chi^{2}(2)=10.18, p<0.01\right)$; [a] with anterior variants: $\left(\chi^{2}(2)=21.04, p<0.001\right)$; [a] with posterior variants: $\left(\chi^{2}(2)=12.92, p<0.01\right) ;[\mathrm{u}]:\left(\chi^{2}(2)=13.97, p<\right.$ $0.001)$ ). The bilinguals produced significantly more target vowels speaking French for [i] (57.5\%), [a] with anterior variants $(74.3 \%)$ and $[\mathrm{u}](63.0 \%)$ than while speaking Algerian Arabic ([i]: $35.9 \%$, [a] with anterior variants: $42.9 \%$ and [u]: $37.5 \%$ ). Regarding the target vowel [a] with posterior variants, the bilinguals substituted [a] more often by [œ] while speaking Algerian Arabic $(39.0 \%)$ than while speaking French $(16.7 \%)$.

\subsection{Vowel centralization in French and code-switching}

As shown in Table 2, for French native speakers, the oral vowel [i] as well as the three nasal vowels $[\tilde{\varepsilon}, \tilde{a}, \tilde{\partial}]$ were least affected by vowel centralization.

Statistical analyses confirmed that vowel centralization in French is vowel dependent $\left(\chi^{2}(9)=28.24, p<0.001\right)$. The vowel [0] is most affected by vowel centralization (29.8\%) 
Table 2: Expt 3. Vowel centralization measured as schwa variant rates (\%) for native and Algerian speakers of French. The last column displays the difference between FR and FR-Alg.

\begin{tabular}{|c|c|c|r|}
\hline Vowel & FR & FR-Alg & $\Delta$ \\
\hline $\mathrm{i}$ & 14.1 & 12.8 & 1.3 \\
$\mathrm{e}$ & 20.9 & 24.4 & -3.5 \\
$\varepsilon$ & 34.1 & 15.9 & 14.2 \\
$\mathrm{a}$ & 34.0 & 15.9 & 14.1 \\
$\mathrm{~J}$ & 39.4 & 20.2 & 19.2 \\
$\mathrm{o}$ & 33.5 & 21.6 & 11.9 \\
$\mathrm{u}$ & 25.0 & 16.2 & 8.8 \\
$\tilde{\varepsilon}$ & 13.6 & 7.7 & 5.9 \\
$\tilde{\mathrm{a}}$ & 17.5 & 8.7 & 8.8 \\
$\tilde{\mathrm{J}}$ & 17.7 & 6.5 & 11.2 \\
\hline
\end{tabular}

Table 3: Vowel centralization (\%) for bilingual French-Algerian speakers in Arabic read and converational CS speech.

\begin{tabular}{|l|c|c|c|c|c|c|}
\hline Vowel & i & i: & a & a: & u & u: \\
\hline Reading & 56.5 & 15.0 & 42.4 & 26.8 & 44.7 & 24.0 \\
CS & 37.9 & 19.7 & 49.0 & 36.4 & 41.1 & 33.0 \\
\hline
\end{tabular}

whereas the vowel $[\tilde{\varepsilon}]$ is least affected by centralization $(10.7 \%)$. With respect to group (FR, FR-Alg), no significant differences regarding vowel centralization are found $\left(\chi^{2}(9)=\right.$ 9.50, $p=0.39$ ).

For the AA part of the study, vowel centralization has been studied in a slightly different way because the vowels [e] and [o] do not have a grapheme correspondence in Arabic. Thus we decided to include the following short and long Arabic vowels in the analysis [i, is, a, a: $\mathrm{u}, \mathrm{u}:]$. The alignment was still carried out with the French acoustic model used for the other experiments. Results are summarized in Table 3. They show that globally long vowels are less often centralized than short vowels. This tendency was confirmed in both speech styles reading and CS.

Globally, the centralization of AA vowels are more noticeable in the short vowels in read speech the CS speech precisely the gap between the front vowel [i] with $56.5 \%$ and its long version with $15.0 \%$. We conclude, the duration of vowels gives more stability to realization and in AA the hyper-articulation in medium and speed speech rate for the read speech boosts the centralization and schwa production. However, this tendency was not confirmed by the statistical analyses $\left(\chi^{2}(1)=\right.$ $1.01, p=0.32$ ).

Statistical analyses indicated that vowel centralization is also vowel dependent in Algerian Arabic $\left(\chi^{2}(5)=30.00, p<\right.$ $0.001)$. The vowel [i:] is less often centralized (17.4\%) than the other vowels i.e. [i, a, a: u, u:] (39.2\%). However, speech style i.e. reading and CS do not have an impact on vowel centralization in Algerian Arabic $\left(\chi^{2}(5)=7.67, p=0.18\right)$.

\section{Discussion and Conclusions}

In this study we examined vowel variants of $[\mathrm{i}, \mathrm{e}, \mathrm{a}, \mathrm{o}, \mathrm{u}]$ as well as vowel centralization in French and Algerian Arabic. With respect to French, we compared two speaker populations: French natives and Algerian-Arabic bilinguals. The Arabic speech was exclusively produced by Algerian-Arabic bilinguals.

Our results showed that, overall, Algerian Arabic-French bilinguals produce as much variability of vowels in French as do French native speakers. There is only one exception to this observation: in French, Algerian Arabic-French bilinguals show less variation for [a] targets than do French native speakers. Algerian Arabic-French bilinguals seem to vary less on low vowels than high vowels. Which leads us to the conclusion that the bilinguals do not reproduce the difference between high and low vowels observed in French native speakers regarding the degree of variation.

French-Algerian Arabic bilinguals showed more variability across all target vowels in Arabic than they did in French. This result suggests that these bilinguals have different production strategies according to the language. The French vowel triangle shows a higher density than does the Arabic vowel triangle. The bilingual speakers in our study adapt to the language and vary their vowels accordingly.

In French natives, the low variability observed for high vowels, especially [i], might be explained by the density of the vowel triangle, notably for the high frontal vowels $[i, y, e, \varepsilon]$, which share a restricted place, hence, low variability of these vowels helps communication. In Algerian Arabic however, as presented above, only three phonological vowels exist $/ \mathrm{i}, \mathrm{a}, \mathrm{u} /$, which each present a short/long duration difference. However, phonetically Algerian Arabic also has the mid front vowel [e:]. The variability observed for [i] in French and Arabic in our data suggests that this mid front vowel is rather a variant of /i/ than /a/ for these Algerian Arabic-French bilinguals.

Finally, with respect to the parallel variants with [ə] in French, our data showed that the vowel [0] is more often centralized compared to the other target vowels. Similar findings were reported in [26] where [0] was found to be close to [œ] which is also a central vowel. Our data in French showed, that FrenchAlgerian Arabic bilinguals centralize vowels in the same way as do French native speakers. However, descriptively we find that in French natives, whose vowel productions are generally more variable, the most stable vowels are $[i, e]$ and the three nasal vowels, whereas in Algerian Arabic-French bilinguals the most stable vowels, next to the nasals, were $[i, a, u]$. The mid vowels $[\mathrm{e}, \varepsilon, \mathrm{\jmath}, \mathrm{o}]$ were frequently aligned with $[ə]$. This might be explained with the Algerian Arabic phonemic vowel system where mid vowels are absent and thus not very important for successful communication. The vowels $[i, a, u]$, on the other hand are important on a phonemic level for Arabic speakers because from a structural point of view Arabic distinguishes for instance word classes verb tenses over vowel variation in similar consonant contexts, hence, vowel variation with a mutual central vowel could be fatal for communication and sentence structure.

With respect to Arabic, our results showed that the target $[i \mathrm{i}]$ is less often centralized than the other vowels. A possible reason for this result might lay in the extreme position of [i:] in the vowel triangle. In order to investigate this hypothesis, further acoustic analyses are needed.

In conclusion, our corpus based analysis suggests tht French-Algerian Arabic bilinguals are able to vary their vowel productions according to the language they speak, thereby adjusting their productions to the respective vowel systems.

\section{Acknowledgements}

This work is supported by the French National Agency for Research as part of the SALSA project (Speech and Language technologies for Security Applications) project under grant ANR-14-CE28-0021 and by the French Investissements d'Avenir-Labex EFL program (ANR-10-LABX-0083). 


\section{References}

[1] B. E. Bullock, Phonetic reflexes of code-switching. Cambridge: Cambridge University Press, 2012, ch. 10, pp. 163-181.

[2] P. Auer, Code-switching in conversation: Language, interaction and identity. Routledge, 2013.

[3] M. Fricke, J. F. Kroll, and P. E. Dussias, "Phonetic variation in bilingual speech: A lens for studying the productioncomprehension link," Journal of memory and language, vol. 89 , pp. $110-137,2016$

[4] F. Grosjean, "A psycholinguistic approach to code-switching: The recognition of guest words by bilinguals," One speaker, two languages: Cross-disciplinary perspectives on code-switching, pp. $259-275,1995$.

[5] L. Isurin, D. Winford, and K. De Bot, Multidisciplinary approaches to code switching. John Benjamins Publishing, 2009, vol. 41.

[6] N. T. Vu, H. Adel, and T. Schultz, "An investigation of codeswitching attitude dependent language modeling," in International Conference on Statistical Language and Speech Processing. Springer Berlin Heidelberg, 2013, pp. 297-308.

[7] A. Laurent, T. Fraga-Silva, L. Lamel, and J.-L. Gauvain, "Investigating techniques for low resource conversational speech recognition," in Acoustics, Speech and Signal Processing (ICASSP), 2016 IEEE International Conference on . IEEE, 2016, pp. 5975-5979.

[8] M. Adda-Decker and L. Lamel, "Pronunciation variants across system configuration, language and speaking style," Speech Communication, vol. 29, no. 2-4, pp. 83-98, 1999.

[9] P. B. d. Mareüil and M. Adda-Decker, "Studying pronunciation variants in French by using alignment techniques," in Seventh International Conference on Spoken Language Processing, 2002.

[10] C. Fougeron and S. Smith, "Illustrations of the IPA: French." Handbook of the International Phonetic Association: A Guide to the Use of the International Phonetic Alphabet, pp. 78-81, 1999.

[11] S. Harrat, K. Meftouh, M. Abbas, and K. Smaïli, "An Algerian dialect: Study and resources," International Journal of Advanced Computer Science and Applications-IJACSA, vol. 7, no. 3, 2016.

[12] D. Amazouz, M. Adda-Decker, and L. Lamel, "The FrenchAlgerian Code-Switching Triggered audio corpus (FACST)," in Proc. Eleventh International Conference on Language Resources and Evaluation LREC 2018, 2018, pp. 1468-1473. [Online]. Available: http://www.lrec-conf.org/proceedings/lrec2018/pdf/ 801.pdf

[13] H. Saadane and N. Habash, "A conventional orthography for Algerian Arabic," in Proceedings of the Second Workshop on Arabic Natural Language Processing, 2015, pp. 69-79.

[14] D. Amazouz, M. Adda-Decker, and L. Lamel, "Addressing Code-Switching in French/Algerian Arabic Speech," in Proc ISCA Interspeech 2017, 2017, pp. 62-66. [Online]. Available: http://dx.doi.org/10.21437/Interspeech.2017-1373

[15] S. Kheder and E. Kaan, "Processing Code-Switching in Algerian Bilinguals: Effects of Language Use and Semantic Expectancy,' Frontiers in psychology, vol. 7, p. 248, 2016.

[16] Ö. Çetinoğlu, "A Code-Switching Corpus of Turkish-German Conversations," in Proceedings of the 11th Linguistic Annotation Workshop, 2017, pp. 34-40.

[17] F. Torreira, M. Adda-Decker, and M. Ernestus, "The Nijmegen corpus of casual French," Speech Communication, vol. 52, no. 3, pp. 201-212, 2010
[18] J.-L. Gauvain, L. Lamel, and G. Adda, "The LIMSI broadcast news transcription system," Speech communication, vol. 37, no. 1-2, pp. 89-108, 2002.

[19] L. Lamel, J.-L. Gauvain, G. Adda, M. Adda-Decker, L. Canseco, L. Chen, O. Galibert, A. Messaoudi, and H. Schwenk, "Speech transcription in multiple languages," in Acoustics, Speech, and Signal Processing, 2004. Proceedings.(ICASSP'04). IEEE International Conference on, vol. 3. IEEE, 2004, pp. iii-757.

[20] G. Gelly, J.-L. Gauvain, L. Lamel, A. Laurent, V. B. Le, and A. Messaoudi, "Language recognition for dialects and closely related languages," Odyssey, Bilbao, Spain, 2016.

[21] L. Lamel, A. Messaoudi, and J.-L. Gauvain, "Automatic speechto-text transcription in Arabic," ACM Transactions on Asian Language Information Processing (TALIP), vol. 8, no. 4, p. 18, 2009.

[22] C. M. White, S. Khudanpur, and J. K. Baker, "An investigation of acoustic models for multilingual code-switching," in Ninth Annual Conference of the International Speech Communication Association, 2008.

[23] E. van der Westhuizen and T. Niesler, "Automatic speech recognition of English-isiZulu code-switched speech from South African soap operas," Procedia Computer Science, vol. 81, pp. 121-127, 2016.

[24] P. Delattre, "An acoustic and articulatory study of vowel reduction in four languages," IRAL-International Review of Applied Linguistics in Language Teaching, vol. 7, no. 4, pp. 295-326, 1969.

[25] G. Khattab, Phonetic accommodation in children's codeswitching. Cambridge: Cambridge University Press, 2009, ch. 9, pp. 149-160.

[26] P. Boula de Mareüil, B. Vieru-Dimulescu, C. Woehrling, and M. Adda-Decker, "Accents étrangers et régionaux en français," Traitement Autom. Lang, vol. 49, no. 3, pp. 135-163, 2008. 